\title{
Effect of Citric Acid and Various Concentrations of Fibronectin on Healing Following Periodontal Flap Surgery in Dogs*
}

\author{
B. A. Smith,† J. S. Smith,‡ R. G. Caffesse,§ C. E. Nasjleti, „ \\ D. E. Lopatin I and C. J. Kowalski ${ }^{\star \star}$
}

Accepted for publication 19 November 1986

\begin{abstract}
THE PURPOSE OF THIS HISTOLOGIC and histometric study was to examine the effect of citric acid and increasing concentrations of fibronectin on new connective tissue attachment following periodontal flap surgery. Full thickness, mucoperiosteal flaps were elevated in six healthy mongrel dogs. Two to $3 \mathrm{~mm}$ of alveolar bone were removed along the buccal aspect of the teeth in the mandible and into the interproximal areas of each surgical site. Cementum was removed from the exposed root surfaces and reference notches were inscribed into the roots at the margin of the recontoured bone. Citric acid, $\mathrm{pH} \mathrm{1.0,} \mathrm{was} \mathrm{applied} \mathrm{to} \mathrm{the}$ instrumented root surfaces for 3 minutes and rinsed with sterile saline. Both the root surfaces and the inner surface of the flap were then bathed in either sterile saline or increasing concentrations $(0.38,0.75$ and $1.5 \mathrm{mg} / \mathrm{ml}$ saline) or exogenous fibronectin. All the flaps were returned to their original preoperative positions, secured using figure 8 sutures with 40 braided silk and allowed to heal. Two dogs per time-point were sacrificed at 1, 2 and 6 weeks after surgery. Block specimens of the surgical sites were demineralized and serial sections prepared for histologic and histometric evaluations. Histologically, tissue sections were examined for: (1) epithelial proliferation and attachment, (2) periodontal fiber organization and maturation, (3) inflammatory cell types, (4) presence or absence of new cementum deposition and (5) degree of vascularity of the tissues. Histometric measurements were taken: (1) from the root surface notch to the apical extent of the junctional epithelium and (2) from the apical extent of the junctional epithelium to the free gingival margin. The four treatment modalities were compared by the use of repeated measurement analysis of variance. When significant differences were found, the Newman-Keuls procedure was used to make individual comparisons between each pair of mean values. Results of the study demonstrated a significant increase in new connective tissue attachment in all surgical sites where exogenous fibronectin had been added, but there was no obvious advantage in increasing the concentration of fibronectin above the plasma level $(0.38 \mathrm{mg} / \mathrm{ml})$.
\end{abstract}

The rationale for periodontal therapy is aimed at elimination of periodontal disease, restoration of the periodontal tissues to a healthy, functional state and the subsequent maintenance of these tissues. The dental

\footnotetext{
* Supported by part by the Veterans Administration.

$\dagger$ Associate Professor, Department of Periodontics, The University of Michigan School of Dentistry, Ann Arbor, MI 48109.

$\ddagger$ Private practice, Prairie Professional Building, 3181 Prairie Street, Grandville, MI 49418.

$\S$ Professor and Chairman, Department of Periodontics, The University of Michigan School of Dentistry.

II Dental Research Program, V. A. Medical Center, Ann Arbor, MI 48105.

II Associate Professor, Dental Research Institute, The University of Michigan.

** Professor, Dental Research Institute, The University of Michigan.
}

literature has clearly demonstrated that present modes of periodontal therapy are successful in achieving these goals; however, the ultimate goal of therapy is the regeneration of the attachment, which is lost during disease.

Histologic evidence of cementogenesis and new connective tissue attachment to previously diseased root surfaces, with the use of citric acid demineralization following root preparation, has been reported in animal and human studies. ${ }^{1-5}$ Fibronectin, when used with citric acid, has been shown to enhance the regeneration of connective tissue attachment, possibly by increasing interactions between exposed root surface collagen, and collagen and fibroblasts within the supporting soft tissue. $^{6}$

The purpose of this histologic and histometric study 
was to examine the effect of citric acid and various concentrations of fibronectin (FN) on new connective tissue attachment following periodontal flap surgery in mongrel dogs.

\section{MATERIALS AND METHODS}

Six adult male mongrel dogs, in good systemic health, were used in this study. The selection of the animals was based upon the presence of an intact dentition, with minimal or no naturally occurring periodontal disease. With the exception of the 1st week postsurgically, the dogs were maintained on a hard diet during the experimental period.

Experimental Materials. Citric acid was obtained in anhydrous form. It was mixed to saturation in sterile saline at room temperature and verified to a $\mathrm{pH}$ of 1.0 with a $\mathrm{pH}$ meter. Fresh solutions of citric acid were prepared prior to each surgery. Fibronectin (FN) was obtained from blood of the experimental dogs. Whole blood was drawn into heparinized vacutainers that were rolled and refrigerated. Within 24 hours after being drawn, the blood was centrifuged at $500 \mathrm{rpm}$ for 5 minutes. The plasma portion was passed through a gelatin sepharose column, washed with phosphate-buffered saline and filtered through a sterile $0.22 \mu$ filter unit. The concentration of the FN was found to be 1.5 $\mathrm{mg} / \mathrm{ml}$. This was determined spectrophotometrically by assuming a $1.0 \%$ extinction coefficient at $280 \mathrm{~mm}$ in a $1.0-\mathrm{cm}$ path equal to 12.8 . The $\mathrm{FN}$ solutions were stored in $2.0 \mathrm{ml}$ vials and kept frozen until the time of surgery. The FN was $>95 \%$ pure as assessed by gel electrophoresis.

Hygienic Phase Procedures. All of the dogs were anesthetized with 3.0 to $5.0 \mathrm{ml}$ of 2.5 Serutal $^{\circledR}$. Preclinical photographs were taken at each of the operative sites in all dogs. Upon clinical evaluation no attachment loss was observed in the operative sites. Subsequently, the teeth were hand scaled and polished. Toothbrushing was performed every 2 to 3 days throughout the experimental period (except for the first 7 days postsurgically when no brushing was done). Additional photographs were taken during and after the hygienic and surgical phases.

Surgical and Laboratory Procedures. A total of 24 surgical sites was used in this study to observe the differences in healing between three successive concentrations of $\mathrm{FN}$, as monitored over postsurgical time intervals of 1,2 and 6 weeks. This allowed two surgical sites for each combination of FN concentration and time interval. The FN concentrations used were: 1.5, 0.75 and $0.38 \mathrm{mg} / \mathrm{ml}$ in saline. The fourth surgical site received only saline, to serve as control. The $0.38 \mathrm{mg} /$ ml FN-saline solution was designated as plasma concentration since natural plasma levels of $\mathrm{FN}$ run between 0.3 and $0.5 \mathrm{mg} / \mathrm{ml}$. The surgical sites consisted of the $\mathrm{P}_{2}-\mathrm{P}_{3}$ and $\mathrm{P}_{4}-\mathrm{M}_{1}$ areas of the buccal aspects of the mandible. Each site consisted of the mesial and distal portions of adjacent teeth together with the interproximal tissue. The interproximal attached gingiva between $\mathrm{P}_{3}$ and $\mathrm{P}_{4}$ was kept intact in order to prevent contamination between anterior and posterior surgical sites (Fig. 1). Each dog was anesthetized using 2 to 3 $\mathrm{ml}$ of Serutal ${ }^{\circledR}(35 \mathrm{mg} / \mathrm{ml})$. Prior to surgery, each area was locally anesthetized with 1.0 to $1.5 \mathrm{ml}$ of a $2.0 \%$ xylocaine-epinephrine solution, 1:50,000. Mucoperiosteal flaps were raised with vertical releasing incisions extending to the mucogingival junctions at the mesial and distal aspects of the surgical sites. Two to $3 \mathrm{~mm}$ of bone were removed along the buccal aspect and extended $2 \mathrm{~mm}$ into the interproximal areas at each site. This was accomplished using a Number 8 round steel bur and curettes. The removal of cementum from the

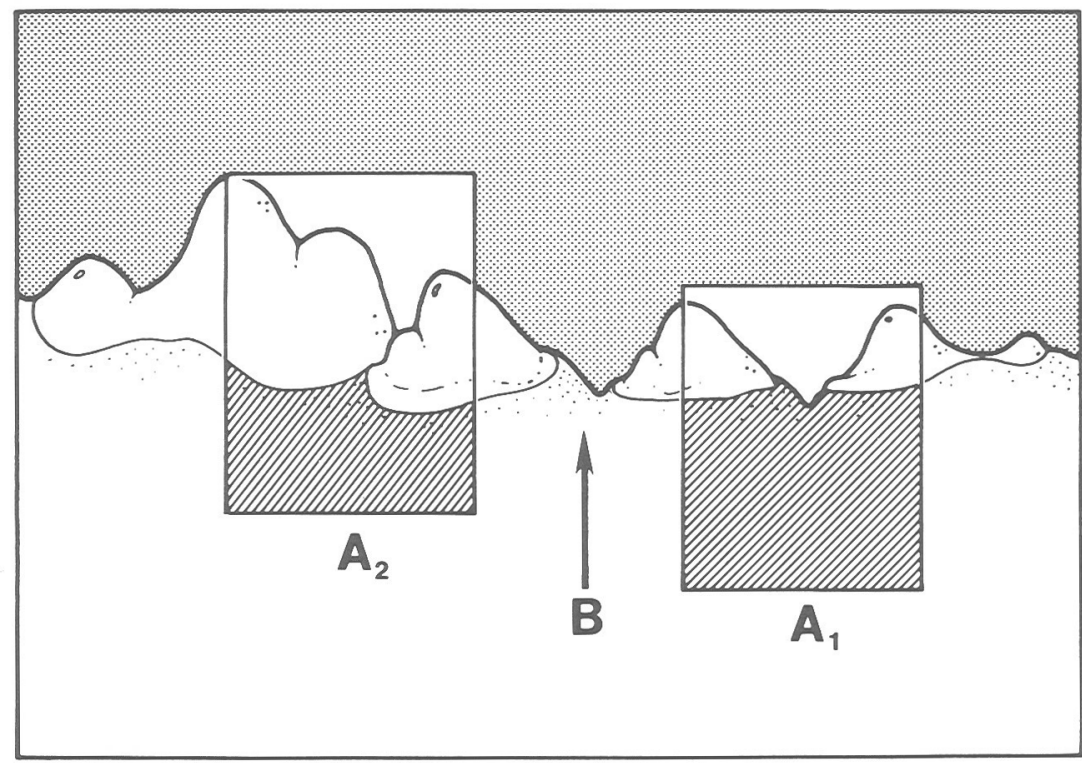

Figure 1. $A_{1}$, surgical site consisting of $P_{2} P_{3} ; A_{2}$, surgical site consisting of $P_{3} P_{4} ; B$, unoperated buffer zone. 
roots was also performed with a combination of the round bur and curettes. Reference notches were inscribed into the roots at the margin of the recontoured bone with a sharpened sickle scaler. These notches were positioned on the buccal aspects of the teeth and extended into the furcation and interproximal areas.

Citric acid was applied to the instrumented root surfaces in all surgical areas using cotton pellets for 3 minutes. These pellets were replaced after 90 seconds. Extreme care was taken to avoid contamination of the bone and soft tissues from the acid solution by covering the reflected flaps and exposed bone with saline-moist, sterile gauze during the procedure. Following a 3-minute demineralization, all areas were thoroughly rinsed with sterile saline. In the sites receiving FN, $1.0 \mathrm{ml}$ of the solutions was applied with a tuberculin syringe. Both the root surfaces and the inner surface of the flap were bathed in fibronectin. Excess solution was absorbed with sterile gauze. All flaps were returned to their original preoperative positions and secured using 4-0 braided silk sutures. Suspensory sutures were used in some areas to guarantee close adaptation of the flaps to the underlying hard tissues. Moderate pressure was applied over the sites for 3 minutes with saline-moist, sterile gauze to enhance flap adaptation and promote the formation of a thin fibrin clot. During the following week all dogs were fed a soft diet, and toothbrushing was stopped in order to avoid disruption of the healing flaps. Sutures were removed 7 days following surgery. No complications were observed. Toothbrushing was then resumed and maintained until sacrifice.

The dogs were sacrificed, two at a time, at 1,2 and 6 weeks following surgery with a lethal overdose of Nembutal $^{\circledR}$. The heads of the animals were perfused with $10 \%$ buffered formalin and refrigerated for 24 hours. The jaws were dissected with the adjacent soft tissues and placed in formalin solution for additional fixation. Prior to demineralization, the jaws were sectioned in small blocks corresponding to the surgical sites. Demineralization was accomplished with $10 \%$ trifluoracetic acid (TFA) over a 10-day period. The demineralized tissue blocks were washed under running water for 24 hours, dehydrated in alcohol, infiltrated and embedded in paraffin, and serially cut in the buccal-lingual plane into 6- $\mu$ sections. The sections were mounted on glass slides and stained with Masson's or Mallory's connective tissue stain and hematoxylin and eosin.

Tissue sections from each of the 24 surgical sites were examined and evaluated blindly using a binocular microscope at $40 \times$ magnification. Descriptive histologic and histometric evaluations were performed. From each surgical site, 14 step-serial sections representing intervals of $0.08 \mathrm{~mm}$ were used. The sections consisted of seven step-serial sections distal to the interproximal midsection, and seven step-serial sections mesial to the midsection. This procedure allowed an equal number of sections for evaluating distal and mesial roots of the surgical sites. Histologically, tissue sections were examined for: (1) epithelial proliferation and attachment; (2) periodontal fiber organization and maturation; (3) inflammatory cell types; (4) presence or absence of new cementum deposition; and (5) degree of vascularity of the tissues. Histometric measurements were made with a Filar micrometer eyepiece, ${ }^{*}$ held parallel to the specimen surface. The eyepiece was calibrated at $40 \times$ magnification using the grid of a hemocytometer. The distances measured were: (1) from the root surface notch to the apical extent of the junctional epithelium and (2) from the apical extent of the junctional epithelium to the free gingival margin. All sections were measured by orienting the vertical axis of the micrometer grid parallel to the root surface. The apex of the root notch was used as the baseline reference point. Each tissue section was measured twice at intervals varying from one to several weeks to determine if errors in measuring would influence the results.

Statistical Evaluation. The four treatment modalities were compared by a repeated measurements analysis of variance $^{7}$ with time of measurement being the grouping factor and the treatment modalities being the repeated measurements factor. When significant differences were found, the Newman-Keuls procedure ${ }^{7}$ was used to make pairwise comparisons between the treatment modalities. This analysis recognized the dog as the experimental unit and allowed each dog to act as his own control for assessing the effectiveness of the various concentrations of FN.

\section{RESULTS}

Healing proceeded uneventfully in the surgical sites. Clinical and histological observations revealed no untoward hard or soft tissue reactions following topical application of citric acid and/or FN.

Histologic. One-week tissue sections, stained with Masson's trichrome and hematoxylin and eosin, demonstrated a fibrinous new attachment to the root composed of fibroblasts, capillaries, macrophages, polymorphonuclear leukocytes (PMNs) and new collagen. The base of the junctional epithelium was always observed coronal to the reference notch in the root. In some specimens, areas of mature, collagenous connective tissue were seen running parallel to the root surface. However, an actual splicing of the two tissues was not yet apparent. In most tissue sections a portion of the original clot, consisting of fibrin, macrophages, PMNs, erythrocytes and necrotic debris, could be observed separating the area of the connective tissue attachment from the base of the junctional epithelium.

Many of the 2-week specimens revealed highly cellular connective tissue adjacent to, and inserting into, the root surface. After 2 weeks the connective tissue

\footnotetext{
* American Optical, Filar micrometer eyepiece, Model No. 424, Buffalo, NY 14215.
} 
displayed increasing amounts of mature collagen fibers attaching into, and coronal to, the notch (Figs. 2 and 3 ). This tissue possessed a dense network of capillaries. However, there were fewer inflammatory cells, and the fibrin clot was no longer present.

Sections from the 6-week sites displayed further increases in the proportion of mature collagen within the attachment area (Fig. 4). Fully formed blood vessels were present, and there were significantly fewer inflammatory cells. Mature collagen fibers could be observed running parallel, askew and perpendicular to the root surface. In the notch, and in some of the areas coronal to the notch, a lighter staining, cementum-like substance was observed over areas of exposed dentin. In most of the specimens fiber orientation was perpendicular to the areas of new cementum.

Histometric. The results of the histometric evaluations are summarized in Tables 1 and 2. Table 1 represents connective tissue reattachment, and Table 2 represents epithelial proliferation. Each of the observations shown represents the average of 14 step-serial sections, and these were the data analyzed by the repeated measurements analysis of variance. In each instance, both the time of measurement factor and the treatment factor were significant $(P<0.001)$. Subsequent analysis by the Newman-Keuls procedure showed that in Table 1 each of the FN treatments differed significantly from the control but not from one another. In Table 2 , the control did not differ significantly from $0.75 \mathrm{mg} / \mathrm{ml}$, and $0.38 \mathrm{mg} / \mathrm{ml}$ did not differ from $1.50 \mathrm{mg} / \mathrm{ml}$.

\section{DISCUSSION}

The study has demonstrated that citric acid and various concentrations of exogenous FN exert statistically significant differences on connective tissue reattachment following periodontal flap surgery in mongrel dogs. The increased concentration of FN was not shown to be significant since increases in coronal levels of connective tissue reattachment were similar in 0.38-, $0.75-$ and $1.5-\mathrm{mg} / \mathrm{ml} \mathrm{FN}$ sites. Thus, there was no obvious advantage in increasing the concentration of FN above plasma level $(0.38 \mathrm{mg} / \mathrm{ml})$. However, it should be stressed that this study examined healing responses to acute wounds. There was no natural or experimental periodontitis present in any of the surgical sites. It should also be stressed that this technique for regeneration therapy is experimental and should not yet be used in practice.

It is not too surprising that the use of FN increased the connective tissue attachment to the root surfaces. Exogenous FN has been used successfully during surgery in humans to produce hemostasis, improve neural and microvascular anastomoses, promote wound healing and serve as a tissue adhesive. ${ }^{8}$ Increased levels of FN are observed naturally in humans during the earliest

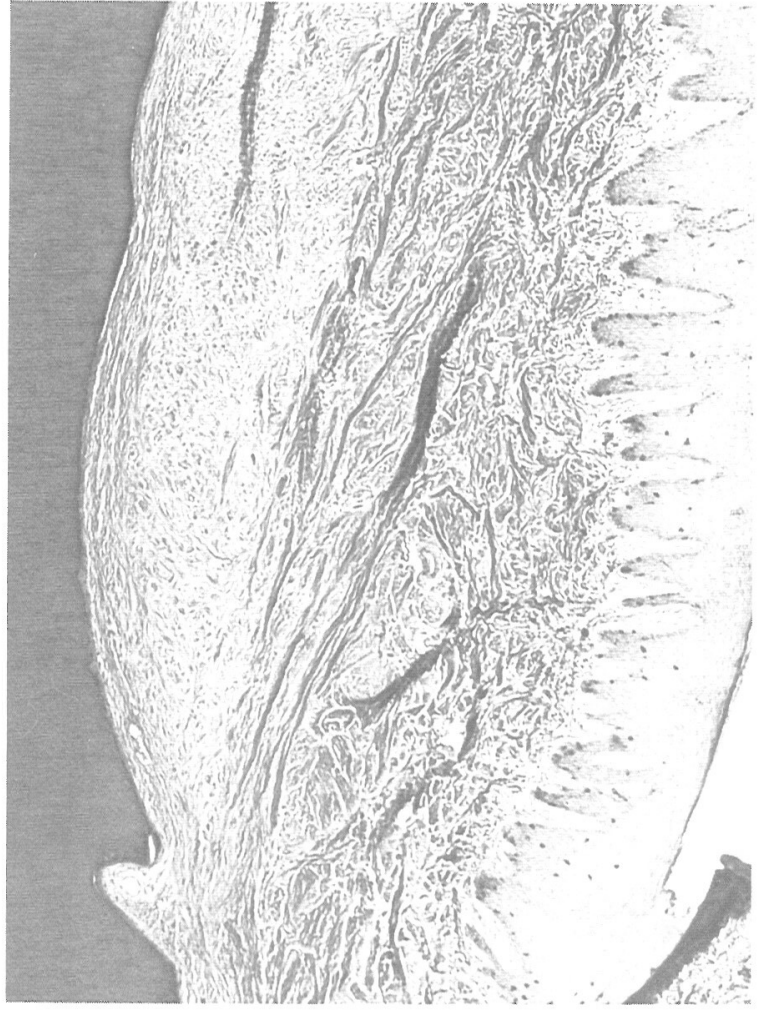

Figure 2. Two weeks postoperatively, $0.38 \mathrm{mg} / \mathrm{ml} \mathrm{FN}$ concentration (magnification $\times 50$ ).

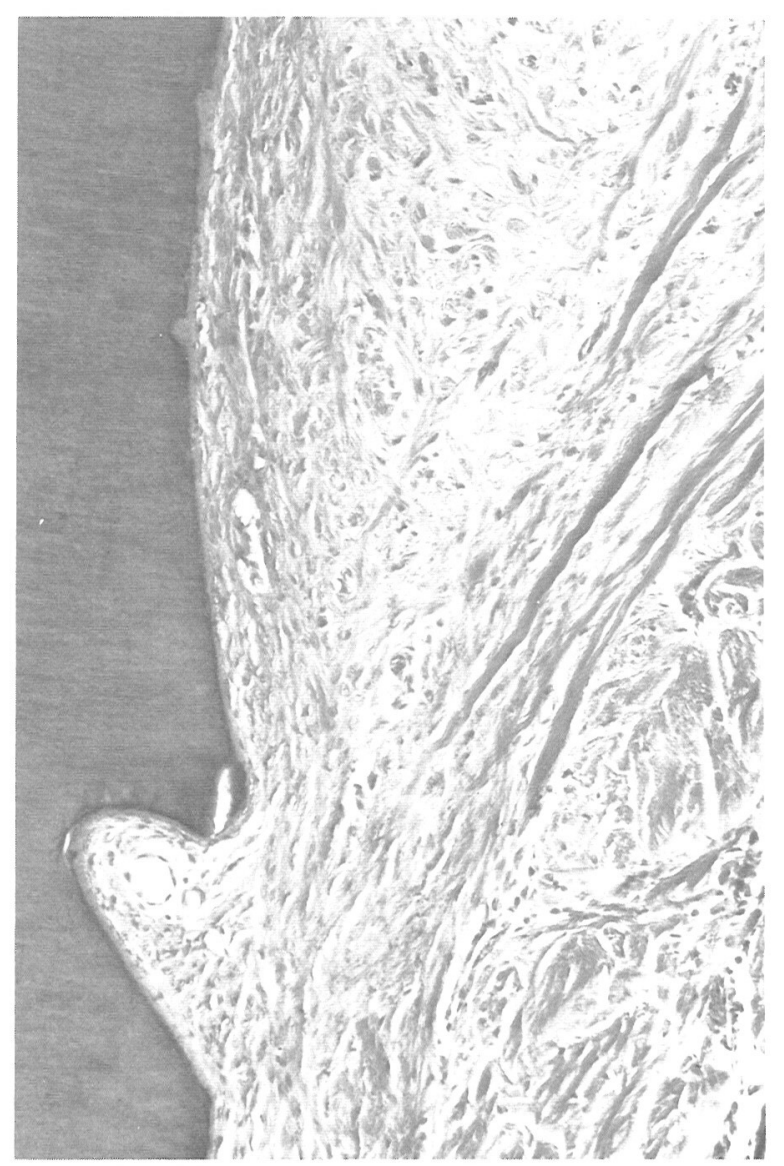

Figure 3. Higher magnification of Figure 2. Two weeks postoperatively, $0.38 \mathrm{mg} / \mathrm{ml} \mathrm{FN}$ concentration (magnification $\times 100$ ). 


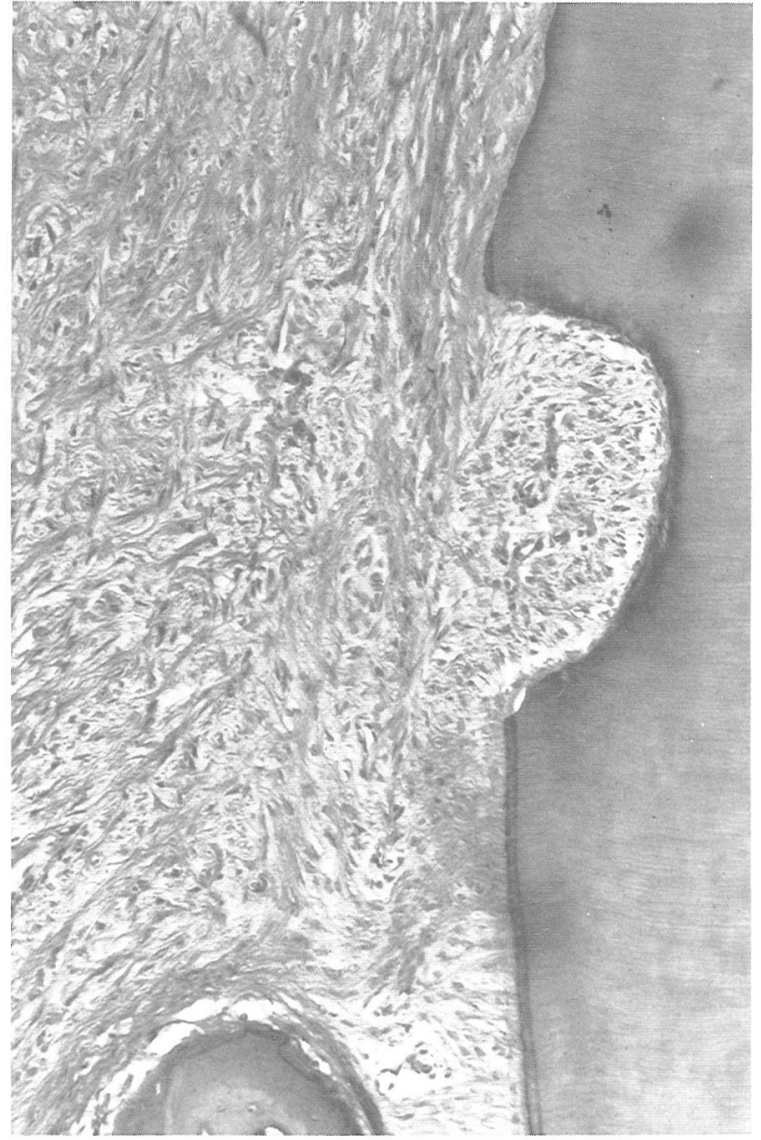

Figure 4. Six weeks postoperatively, $0.75 \mathrm{mg} / \mathrm{ml} \mathrm{FN}$ concentration (magnification $\times 100$ ).

Table 1

Histometric Measurements from the Root Surface Notch to the Base of the Junctional Epithelium for the Four Treatment Modalities (in $\mathrm{mm}$ ) by Repeated Measurements Analyses of Variance

\begin{tabular}{|c|c|c|c|c|}
\hline & \multirow[t]{2}{*}{ Control } & \multicolumn{3}{|c|}{$\begin{array}{c}\text { Fibronectin } \\
\text { Concentration }(\mathrm{mg} / \mathrm{ml})\end{array}$} \\
\hline & & 0.38 & 0.75 & 1.50 \\
\hline & 0.55 & 1.33 & 1.30 & 1.06 \\
\hline \multicolumn{5}{|l|}{ One week } \\
\hline & 0.61 & 1.39 & 1.26 & 1.12 \\
\hline & 0.38 & 0.96 & 0.79 & 0.87 \\
\hline \multicolumn{5}{|l|}{ Two weeks } \\
\hline & 0.34 & 0.92 & 0.73 & 0.93 \\
\hline & 0.57 & 0.95 & 1.01 & 1.35 \\
\hline \multicolumn{5}{|l|}{ Six weeks } \\
\hline & 0.55 & 1.01 & 1.07 & 1.31 \\
\hline
\end{tabular}

$\longrightarrow$ No significant difference (Newman-Keuls).

stages of wound repair and organization. ${ }^{9}$ Until recently it was assumed that FN was involved primarily with connective tissue interactions, while the glycoprotein laminin mediated epithelial reactions. This is not always the case. Fibronectin has been shown to provide a suitable substrate for epithelial cell migration during
Table 2

Histometric Measurements from the Base of the Junctional Epithelium to the Free Gingival Margin for the Four Treatment Modalities (in mm) by Repeated Measurements Analyses of Variance

\begin{tabular}{|c|c|c|c|c|}
\hline & \multirow[t]{2}{*}{ Control } & \multicolumn{3}{|c|}{$\begin{array}{c}\text { Fibronectin } \\
\text { Concentration }(\mathrm{mg} / \mathrm{ml})\end{array}$} \\
\hline & & 0.38 & 0.75 & 1.50 \\
\hline & 0.70 & 1.90 & 0.42 & 1.65 \\
\hline \multirow[t]{3}{*}{ One week } & & & & \\
\hline & 0.72 & 1.94 & 0.44 & 1.71 \\
\hline & 1.40 & 2.22 & 1.17 & 1.84 \\
\hline \multirow[t]{3}{*}{ Two weeks } & & & & \\
\hline & 1.36 & 2.26 & 1.11 & 1.76 \\
\hline & 1.66 & 1.31 & 1.46 & 1.86 \\
\hline \multicolumn{5}{|l|}{ Six weeks } \\
\hline & 1.72 & 1.25 & 1.52 & 1.92 \\
\hline
\end{tabular}

wound closure. Epidermal cells can migrate over a matrix of fibrin and FN, even though the matrix lacks laminin or Type IV collagen. ${ }^{10,11}$ Fibronectin has been observed, using immunofluorescence, in migrating epithelial cells of corneal wounds, and application of additional $\mathrm{FN}$ enhanced this migration. ${ }^{12}$

No collars were taken from the flaps in the study, to remove sulcular epithelium. The gingival flaps were too thin and the sulci were very shallow. However, since 2 to $3 \mathrm{~mm}$ of alveolar bone were removed, at least that much connective tissue on the inner aspect of the flap was repositioned to the roots. Although FN was used in this study to promote reattachment between flap collagen and demineralized root collagen, it seems likely that it would also have had some effect on any epithelium remaining on the inside of the flap following surgery. Nonetheless, no clear pattern of epithelial behavior was detected in the study.

The main function of FN appears to be the promotion of cell adhesion to various biological substances. Different studies also have revealed that FN exerts a chemoattractive effect on fibroblasts and mesenchymal cells. This may play an important role in the development and remodeling of tissues in wound repair. ${ }^{13,14}$ Fibronectin is a sensitive target of neutral proteases present at sites of inflammation. These proteases cause the loss of the biological properties of FN. ${ }^{15}$ Vercellotti et al. ${ }^{16}$ found that FN, altered by neutrophil release products, caused an increased adherence of PMNs to endothelial cells. Therefore, such altered FN might serve as an amplifier in inflammation. One reason for increased levels of new connective tissue attachment may be that FN was present in sufficient quantities to avoid complete inactivation by neutral proteases.

The opsonic properties of FN are important in the 
removal of bacteria and necrotic debris during wound organization and healing. ${ }^{17}$ Greater than normal concentration of FN may facilitate the removal of clots and debris after surgery.

Regeneration of cementum and connective tissue attachment on previously diseased root surfaces is possible following surgical procedures. ${ }^{1-6}$ A combination of citric acid and $\mathrm{FN}$ appears to produce the best results for gains in new attachment. In a recent study, ${ }^{6}$ it was found that $\mathrm{FN}$ alone produced little more new attachment than did control teeth treated without FN or citric acid. When FN was combined with citric acid, new attachment was much greater than that found with citric acid alone. This finding was attributed to enhanced adhesion between collagen fibers in the flap and fibers along the demineralized root surface. ${ }^{6}$ Boyko et al. ${ }^{18}$ found increased attachment of cultured fibroblasts to root surfaces demineralized by acids. They concluded that FN, synthesized by the fibroblasts, was able to react with the exposed collagen substrate created on the root by demineralization. Fernyhough and Page ${ }^{19}$ reported enhanced attachment of cultured fibroblasts on instrumented teeth with citric acid or FN. Attachment was similar between FN and citric acid; however, no comparison was made with the agents used in combination. Polson and Proye ${ }^{20}$ suggested that FN may have potential significance in facilitating the attachment of the connective tissues to demineralized root surfaces through collagen-fibrin interactions. They concluded that FN probably is not the critical agent for successful new connective tissue attachment.

The proposed mechanism in connective reattachment to demineralized roots involves a "splicing" of collagen fibers of the flap and of the root surface. Until recently there was little actual proof that this splicing occurred. In an ultrastructural study, Frank et al. ${ }^{21}$ examined human teeth treated with flap surgery and citric acid application. They observed and described two types of connective tissue attachment. In the first type, there was cementum formation with functionally aligned Sharpey's fibers. The second type displayed a mineralized layer of decalcified dentin-collagen spliced with fibers, which had been secreted by fibroblasts within the flap. If splicing is to occur, close flap adaptation after surgery is essential. Animal studies have shown enhanced connective tissue attachment in flaps that were closely adapted compared with control areas with spaces between the root surface and the flap. ${ }^{22}$

The analyses employed in this study are well-documented in Winer's text, ${ }^{7}$ and we suggest that this approach may be appropriate for use in other studies employing a similar experimental design. The number of experimental animals in each cell of Table 1 and/or Table 2 is often necessarily small due to such things as financial constraints, and this can seriously compromise the use of more traditional methods. If, for example, we had decided to compare the treatment mo- dalities by doing paired $t$ tests at each time of measurement, since only two animals were available for analysis at a given time, the resulting $t$ statistics would have been a single degree of freedom. This makes reliance on such tests somewhat questionable even if Bonferroni's correction is applied to handle the multiple-test problem. The $t$ distribution with one degree of freedom is also known as the Cauchy distribution and it provides statisticians with an example of a distribution having a number of unsatisfactory properties for inference; e.g., it has no finite moments (mean, standard deviation, etc.). Recognizing the experimental design as a twofactor experiment with repeated measures on one factor obviates this problem. Of course, large sample sizes would produce more powerful tests, and the NewmanKeuls procedure plays the role of Bonferroni's correction, controlling the overall level of significance of the pairwise tests at a specific value. For problems of the size considered in this paper, the computations are easily accomplished with the aid of a simple calculator. For larger problems, computer programs are readily available, e.g., BMDP2V.

\section{CONCLUSIONS}

Within the limits of this study it may be concluded that:

1. A significant increase in connective tissue reattachment occurred in all experimental sites where exogenous fibronectin had been added.

2. There was no obvious advantage in increasing the concentration of exogenous FN above plasma level.

\section{REFERENCES}

1. Register, A. A., and Burdick, F. A.: Accelerated reattachment with cementogenesis in dentin demineralized in situ. II. Defect repair. J Periodontol 47: 497, 1976.

2. Cole, R. T., Crigger, M., Bogle, G., et al: Connective tissue regeneration to periodontally diseased teeth. A histological study. $J$ Periodont Res 15: 1, 1980.

3. Crigger, M., Bogle, G., Nilveus, R., et al.: The effect of topical citric acid application on the healing of experimental furcation defects in dogs. $J$ Periodont Res 13: 538, 1978.

4. Nilveus, R., Bogle, G., Crigger, M., et al.: The effect of topical citric acid application on the healing of experimental furcation defects in dogs. II. Healing after repeated surgery. J Periodont Res 15: 544, 1980.

5. Shiloah, J.: The clinical effects of citric acid and laterally positioned pedicle grafts in the treatment of denuded root surfaces. A pilot study. J Periodontol 51: 652, 1980.

6. Caffesse, R. G., Holden, M. J., Kon, S., and Nasjleti, C. E.: The effect of citric acid and fibronectin application on healing following surgical treatment of naturally occurring periodontal disease in Beagle dogs. J Clin Periodontol 12: 578, 1985.

7. Winer, B. J.: Two-Factor Experiments with Repeated Measures on One Factor. Statistical Principles in Experimental Design, pp 302318. New York, McGraw-Hill, 1962.

8. Matras, $H .:$ The use of a fibrin sealant in oral and maxillofacial surgery. J Oral Maxillofac Surg 40: 617, 1982.

9. Viljanto, J., Penttinen, R., and Raekallio, J.: Fibronectin in early phases of wound healing. Acta Chir Scand 147: 7, 1981.

10. Clark, R. A., Lanigan, J. M., DellaPelle, P., et al.: Fibronectin and fibrin provide a provisional matrix for epidermal cell migration 
during wound reepithelialization. J Invest Dermatol 79: 264, 1982.

11. Donaldson, D. J., and Mahan, J. T.: Fibrinogen and fibronectin as substrates for epidermal cell migration during wound closure. J Cell Sci 62: 117, 1983.

12. Nishida, T., Nakagawa, S., Nishibayashi, C., et al.: Fibronectin enhancement of corneal epithelial wound healing of rabbits in vivo. Arch Ophthalmol 102: 455, 1984.

13. Kleinman, $H .:$ Interactions between connective tissue matrix macromolecules. Connect Tissue Res 10: 61, 1982.

14. Mensing, H., Pontz, B. F., Müller, P. K., and Gauss-Müller, V.: A study on fibroblast chemotaxis using fibronectin and conditioned medium as chemoattractants. Eur J Cell Biol 29: 268, 1983.

15. Baum, B., and Wright, W.: Demonstration of fibronectin as a major extracellular protein of human gingival fibroblasts. $J$ Dent Res 59: $631,1980$.

16. Vercellotti, G. M., McCarthy, J., Furch, L. T., et al.: Inflamed fibronectin: An altered fibronectin enhances neutrophil adhesion. Blood 62: 1063, 1983.

17. Mosesson, M.: The role of fibronectin in monocyte/macro- phage function. Prog Clin Biol Res 154: 155, 1984.

18. Boyko, G. A., Brunette, D. M., and Melcher, A. H.: Cell attachment to demineralized root surfaces in vitro. $J$ Periodont Res 15: 297,1980 .

19. Fernyhough, W., and Page, R. C.: Attachment, growth and synthesis by human fibroblasts on demineralized or fibronectintreated normal and diseased tooth roots. J Periodontol 54: 133, 1983.

20. Polson, A. M., and Proye, M. P.: Fibrin linkage: a precursor for new attachment. J Periodontol 54: 141, 1983.

21. Frank, R. M., Fiore-Donno, G., and Cimasoni, G.: Cementogenesis and soft tissue attachment after citric acid treatment in a human. An electron microscopic study. J Periodontol 54: 389, 1983.

22. Gara, G., and Adams, D.: The effect of notching and citric acid on healthy root surfaces in dogs. J Periodont Res 19: 100, 1984.

Send reprint requests to: Dr. B. A. Smith, Department of Periodontics, the University of Michigan School of Dentistry, Ann Arbor, MI 48109.

\section{Announcement}

The NORTHEASTERN SOCIETY OF PERIODONTISTS, INC.

The Northeastern Society of Periodontists, Inc. announces a joint meeting with the Gnathological Society.

SpEakers: Drs. Patrick Pierce, Jay Siebert and Arnold Weisgold

Place: The Hotel Pierre

New York, New York

DATE: $\quad$ November 13, 1987

For further information, write to: Dr. Irwin W. Scopp, SecretaryTreasurer, Northeastern Society of Periodontists, 110 Bleecker St New York, NY 10012. 